\title{
Neutralization of SARS-CoV-2 spike 69/70 deletion, E484K and N501Y variants by BNT162b2 vaccine-elicited sera
}

\author{
Xuping Xie ${ }^{1,8}$, Yang Liu, ${ }^{1,8}$, Jianying Liu'2,3,8, Xianwen Zhang1, Jing Zou', Camila R. Fontes-Garfias ${ }^{1}$, \\ Hongjie Xia ${ }^{1}{ }^{1}$, Kena A. Swanson ${ }^{4}$, Mark Cutler ${ }^{4}$, David Cooper ${ }^{4}$, Vineet D. Menachery ${ }^{2,3}$, \\ Scott C. Weaver $\mathbb{B}^{2,3}$, Philip R. Dormitzer $\mathbb{1}^{4 凶}$ and Pei-Yong Shi ${ }^{1,3,5,6,7 凶}$
}

\begin{abstract}
We engineered three severe acute respiratory syndrome coronavirus 2 (SARS-CoV-2) viruses containing key spike mutations from the newly emerged United Kingdom (UK) and South African (SA) variants: N501Y from UK and SA; 69/70-deletion + N501Y + D614G from UK; and E484K + N501Y + D614G from SA. Neutralization geometric mean titers (GMTs) of 20 BTN162b2 vaccine-elicited human sera against the three mutant viruses were 0.81 - to 1.46 -fold of the GMTs against parental virus, indicating small effects of these mutations on neutralization by sera elicited by two BNT162b2 doses.
\end{abstract}

We previously reported that BNT162b2, a nucleoside-modified RNA vaccine that encodes the SARS-CoV-2 full-length, prefusion-stabilized spike glycoprotein, elicited dose-dependent SARS-CoV-2-neutralizing GMTs that were similar to or higher than the GMT of a panel of SARS-CoV-2 convalescent human serum samples ${ }^{1}$. We subsequently reported that, in a randomized, placebo-controlled trial of approximately 44,000 participants 16 years of age or older, a two-dose regimen of BNT162b2 conferred 95\% protection against Coronavirus Disease 2019 (COVID-19) ${ }^{2}$.

Since the previously reported studies were conducted, rapidly spreading variants of SARS-CoV-2 have arisen in the UK, SA and other regions ${ }^{3,4}$. These variants have multiple mutations in their spike glycoproteins, which are key targets of virus-neutralizing antibodies. The emerged spike mutations have raised concerns of vaccine efficacy against these new strains. The goal of this study was to examine the effect of several key spike mutations from the UK and SA strains on BNT162b2 vaccine-elicited neutralization.

Using an infectious complementary DNA (cDNA) clone of SARS-CoV-2 (ref. ${ }^{5}$ ), we engineered three spike mutant viruses on the genetic background of clinical strain USA-WA1/2020 (Supplementary Fig. 1). 1) Mutant N501Y virus contains the N501Y mutation that is shared by both the UK and SA variants. This mutation is located in the viral receptor-binding domain (RBD) for cell entry, increases binding to the angiotensin-converting enzyme 2 receptor and enables the virus to expand its host range to infect mice $^{5,6}$. 2) Mutant $\Delta 69 / 70+\mathrm{N} 501 \mathrm{Y}+\mathrm{D} 614 \mathrm{G}$ virus contains two additional changes present in the UK variants: amino acid 69 and 70 deletion $(\Delta 69 / 70)$ and D614G substitution. Amino acids 69 and 70 are located in the $\mathrm{N}$-terminal domain of the spike S1 fragment; deletion of these residues might allosterically change S1 conformation ${ }^{6}$. The D614G mutation is dominant in circulating strains around the world ${ }^{78}$. 3) Mutant E484K+N501Y+D614G virus additionally contains the E484K substitution, which is also located in the viral RBD. The E484K substitution alone confers resistance to several monoclonal antibodies ${ }^{9,10}$. Compared to the wild-type (WT) USA-WA1/2020 strain, the three mutant viruses showed similar plaque morphologies on Vero E6 cells (Supplementary Fig. 2).

We tested a panel of human sera from 20 participants in the previously reported clinical trial ${ }^{1,2}$, drawn 2 or 4 weeks after immunization with two 30- $\mu$ g doses of BNT162b2 spaced 3 weeks apart (Supplementary Fig. 3). All neutralization assays were done with the same20serasamples, with thetwo experiments(asdescribedintheFig. 1 legend) done at different times. Each serum was tested for neutralization of WT USA-WA1/2020 strain and the three mutant viruses by a $50 \%$ plaque-reduction neutralization assay $\left(\mathrm{PRNT}_{50}\right.$; Supplementary Tables 1 and 2). All sera showed equivalent neutralization titers between the WT and mutant viruses, with differences of four-fold or less (Fig. 1). Notably, ten out of the 20 sera had neutralization titers against mutant $\Delta 69 / 70+\mathrm{N} 501 \mathrm{Y}+\mathrm{D} 614 \mathrm{G}$ virus that were twice their titers against the WT virus (Fig. 1b), whereas six out of the 20 sera had neutralization titers against mutant $\mathrm{E} 484 \mathrm{~K}+\mathrm{N} 501 \mathrm{Y}+\mathrm{D} 614 \mathrm{G}$ virus that were half their titers against the $\mathrm{WT}$ virus (Fig. 1c). The ratios of the neutralization GMTs of the sera against the N501Y, $\Delta 69 / 70+\mathrm{N} 501 \mathrm{Y}+\mathrm{D} 614 \mathrm{G}$ and $\mathrm{E} 484 \mathrm{~K}+\mathrm{N} 501 \mathrm{Y}+\mathrm{D} 614 \mathrm{G}$ viruses to their GMTs against the USA-WA1/2020 virus were $1.46,1.41$ and 0.81 , respectively (Supplementary Fig. 4).

Consistent with other recent reports of the neutralization of SARS-CoV-2 variants or corresponding pseudoviruses by convalescent or post-immunization sera ${ }^{11,12}$, the neutralization GMT of the serum panel against the virus with three mutations from the SA variant $(\mathrm{E} 484 \mathrm{~K}+\mathrm{N} 501 \mathrm{Y}+\mathrm{D} 614 \mathrm{G})$ was slightly lower than the neutralization GMTs against the N501Y virus or the virus with three mutations from the UK variant $(\Delta 69 / 70+\mathrm{N} 501 \mathrm{Y}+\mathrm{D} 614 \mathrm{G})$. However, the magnitude of the differences in neutralization GMTs against any of the mutant viruses in this study was small (0.81- to 1.41 -fold), as compared to the greater than four-fold differences in

'Department of Biochemistry and Molecular Biology, University of Texas Medical Branch, Galveston, TX, USA. ${ }^{2}$ Departments of Microbiology and Immunology, University of Texas Medical Branch, Galveston, TX, USA. ${ }^{3}$ Institute for Human Infection and Immunity, University of Texas Medical Branch, Galveston, TX, USA. ${ }^{4}$ Pfizer, Pearl River, NY, USA. ${ }^{5}$ nnstitute for Translational Sciences, University of Texas Medical Branch, Galveston, TX, USA. 'Sealy Institute for Vaccine Sciences, University of Texas Medical Branch, Galveston, TX, USA. ${ }^{7}$ Sealy Center for Structural Biology \& Molecular Biophysics, University of Texas Medical Branch, Galveston, TX, USA. ${ }^{8}$ These authors contributed equally: Xuping Xie, Yang Liu, Jianying Liu.

凶e-mail: philip.dormitzer@pfizer.com; peshi@utmb.edu 

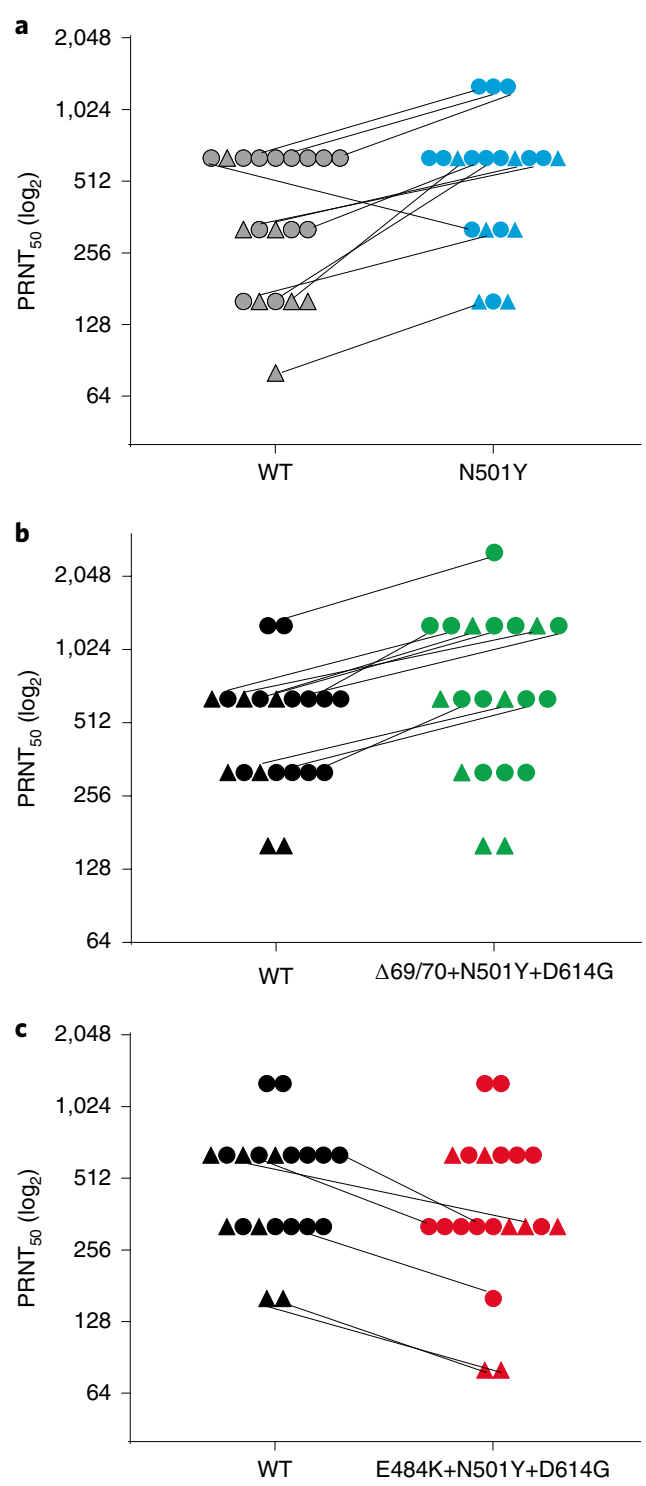

Fig. 1 | PRNT $_{50}$ s of 20 BNT162b2-vaccinated human sera against $\mathrm{WT}$ and mutant SARS-CoV-2. a, WT (USA-WA1/2020) and mutant N501Y. b, WT and $\Delta 69 / 70+N 501 Y+$ D614G. c, WT and E484K + N501Y + D614G. Seven (triangles) and 13 (circles) sera were drawn 2 and 4 weeks after the second dose of vaccination, respectively. Sera with different PRNT $_{50} \mathrm{~s}$ against WT and mutant viruses are connected by lines. Results in a were from one experiment; results in $\mathbf{b}$ and $\mathbf{c}$ were from another set of experiments. Each data point is the average of duplicate assay results.

hemagglutination-inhibition titers that have been used to signal potential need for a strain change in influenza vaccines ${ }^{13}$.

A limitation of the current study is that the engineered viruses do not include the full set of spike mutations found in the UK or SA variants ${ }^{3,4}$. Nevertheless, preserved neutralization of N501Y, $\Delta 69 / 70+\mathrm{N} 501 \mathrm{Y}+\mathrm{D} 614 \mathrm{G}$ and $\mathrm{E} 484 \mathrm{~K}+\mathrm{N} 501 \mathrm{Y}+\mathrm{D} 614 \mathrm{G}$ viruses by BNT162b2 vaccine-elicited human sera is consistent with preserved neutralization of a panel of 15 pseudoviruses bearing spikes with other single mutations found in circulating SARS-CoV-2 strains ${ }^{14}$. The emergence of the common mutation N501Y from different geographical regions, as well as the previously emerged globally dominant D614G mutation, suggest that these mutations might improve viral fitness, as recently demonstrated for the increased viral transmission by the D614G mutation in animal models ${ }^{7,15}$. The biological functions of N501Y and the other mutations (such as $\Delta 69 / 70$ and E484K) remain to be defined for viral replication, pathogenesis and/ or transmission in animal models. A second limitation of the study is that no serological correlate of protection against COVID-19 has been defined. Therefore, predictions about vaccine efficacy based on neutralization titers require assumptions about the levels of neutralization and roles of humoral and cell-mediated immunity in vaccine-mediated protection. Clinical data are needed for firm conclusions about vaccine effectiveness against variant viruses.

The ongoing evolution of SARS-CoV-2 necessitates continuous monitoring of the significance of changes for vaccine efficacy. This surveillance should be accompanied by preparations for the possibility that future mutations might necessitate changes to vaccine strains. The serological criteria for strain changes of influenza vaccine have been well accepted ${ }^{16}$. For COVID-19, such vaccine updates would be facilitated by the flexibility of messenger RNA-based vaccine technology.

\section{Online content}

Any methods, additional references, Nature Research reporting summaries, source data, extended data, supplementary information, acknowledgements, peer review information; details of author contributions and competing interests; and statements of data and code availability are available at https://doi.org/10.1038/ s41591-021-01270-4.

Received: 8 January 2021; Accepted: 28 January 2021; Published online: 8 February 2021

\section{References}

1. Walsh E. E. et al. Safety and immunogenicity of two RNA-based Covid-19 vaccine candidates. N. Engl. J. Med. 383, 2439-2450 (2020).

2. Polack F. P. et al. Safety and efficacy of the BNT162b2 mRNA Covid-19 vaccine. N. Engl. J. Med. 383, 2603-2615 (2020).

3. MRC Centre for Global Infectious Disease Analysis. Report 42 - Transmission of SARS-CoV-2 lineage B.1.1.7 in England: insights from linking epidemiological and genetic data. https://www.imperial.ac.uk/mrc-global-infectiousdisease-analysis/covid-19/report-42-sars-cov-2-variant/ (2021).

4. Tegally H. et al. Emergence and rapid spread of a new severe acute respiratory syndrome-related coronavirus 2 (SARS-CoV-2) lineage with multiple spike mutations in South Africa. Preprint at https://www.medrxiv. org/content/10.1101/2020.12.21.20248640v1 (2020).

5. Xie X. et al. An infectious cDNA clone of SARS-CoV-2. Cell Host Microbe 27, 841-848 (2020).

6. Wrapp, D. et al. Cryo-EM structure of the 2019-nCoV spike in the prefusion conformation. Science 367, 1260-1263 (2020).

7. Plante J. A. et al. Spike mutation D614G alters SARS-CoV-2 fitness. Nature https://doi.org/10.1038/s41586-020-2895-3 (2020).

8. Korber B. et al. Tracking changes in SARS-CoV-2 spike: evidence that D614G increases infectivity of the COVID-19 virus. Cell 182, 812-827 (2020).

9. $\mathrm{Ku}, \mathrm{Z}$. et al. Molecular determinants and mechanism for antibody cocktail preventing SARS-CoV-2 escape. Nat. Commun. 12, 469 (2021).

10. Baum, A. et al. Antibody cocktail to SARS-CoV-2 spike protein prevents rapid mutational escape seen with individual antibodies. Science 369, 1014-1018 (2020).

11. Wibmer C. K. et al. SARS-CoV-2 501Y.V2 escapes neutralization by South African COVID-19 donor plasma. Preprint at bioRxiv https://www.biorxiv. org/content/10.1101/2021.01.18.427166v1 (2021).

12. Wang Z. et al. mRNA vaccine-elicited antibodies to SARS-CoV-2 and circulating variants. Preprint at bioRxiv https://www.biorxiv.org/content/10.11 01/2021.01.15.426911v1 (2021).

13. Smith, D. J. et al. Mapping the antigenic and genetic evolution of influenza virus. Science 305, 371-376 (2004).

14. Sahin U. et al. BNT162b2 induces SARS-CoV-2-neutralising antibodies and T cells in humans. Preprint at https://www.medrxiv.org/content/10.1101/2020. 12.09.20245175v1 (2020).

15. Hou Y. J. et al. SARS-CoV-2 D614G variant exhibits efficient replication ex vivo and transmission in vivo. Science 370, 1464-1468 (2020).

16. Trombetta, C. M., Perini, D., Mather, S., Temperton, N. \& Montomoli, E. Overview of serological techniques for influenza vaccine evaluation: past, present and future. Vaccines 2, 707-734 (2014).

Publisher's note Springer Nature remains neutral with regard to jurisdictional claims in published maps and institutional affiliations.

(c) The Author(s), under exclusive licence to Springer Nature America, Inc. 2021 


\section{Methods}

Construction of isogenic viruses. Three recombinant SARS-CoV-2 mutants (N501Y, $\Delta 69 / 70-\mathrm{N} 501 \mathrm{Y}+\mathrm{D} 614 \mathrm{G}$ and E484K + N501Y + D614G in spike protein) were prepared on the genetic background of an infectious cDNA clone derived from clinical strain WA1 (2019-nCoV/USA_WA1/2020) ${ }^{5}$ by following the polymerase chain reaction-based mutagenesis protocol as reported previously ${ }^{7}$. The full-length infectious cDNAs were in vitro ligated and used as templates to transcribe full-length viral RNA. Mutant viruses (P0) were recovered on day 2 from Vero E6 cells after electroporation of the in vitro RNA transcripts. P1 viruses were harvested as stocks by passaging the P0 virus once on Vero E6 cells. The titers of P1 viruses were determined by plaque assay on Vero E6 cells. The genome sequences of the P1 viruses were validated by Sanger sequencing. The detailed protocol was recently reported ${ }^{17}$.

Serum specimens and neutralization assay. Serum samples were collected from BNT162b2 vaccinees participating in the phase 1 portion of the ongoing phase 1/2/3 clinical trial (ClinicalTrials.gov identifier: NCT04368728). The protocol and informed consent were approved by institutional review boards for each of the investigational centers participating in the study. The study was conducted in compliance with all International Council for Harmonisation Good Clinical Practice guidelines and the ethical principles of the Declaration of Helsinki.

The immunization and serum collection regimens are illustrated schematically in Supplementary Fig. 3. A conventional (non-fluorescent) plaque-reduction neutralization assay was performed to quantify the serum-mediated virus suppression as previously reported ${ }^{18}$. Briefly, each serum was two-fold serially diluted in culture medium, with the first dilution of 1:40 (dilution range of 1:40 to $1: 1280$ ). The diluted sera were incubated with 100 plaque-forming units of WT or mutant viruses at $37^{\circ} \mathrm{C}$ for $1 \mathrm{~h}$, after which the serum-virus mixtures were inoculated onto Vero E6 cell monolayer in six-well plates. After $1 \mathrm{~h}$ of infection at $37^{\circ} \mathrm{C}, 2 \mathrm{ml}$ of $2 \%$ SeaPlaque agar (Lonza) in DMEM containing $2 \% \mathrm{FBS}$ and $1 \%$ penicillin-streptomycin was added to the cells. After $2 \mathrm{~d}$ of incubation, $2 \mathrm{ml}$ of $2 \%$ SeaPlaque agar in DMEM containing $2 \%$ FBS, $1 \%$ penicillin-streptomycin and $0.01 \%$ neutral red (Sigma-Aldrich) were added on top of the first layer. After another $16 \mathrm{~h}$ of incubation at $37^{\circ} \mathrm{C}$, plaque numbers were counted. The minimal serum dilution that inhibits $50 \%$ of plaque counts is defined as the $\mathrm{PRNT}_{50}$. Each serum was tested in duplicates. The $\mathrm{PRNT}_{50}$ assay was performed at the Biosafety Level-3 facility with the approval from the Institutional Biosafety Committee at the University of Texas Medical Branch.

Statistics. No statistical analysis was performed in the study.

Reporting Summary. Further information on research design is available in the Nature Research Reporting Summary linked to this article.

\section{Data availability}

The data that support the findings of this study are available from the corresponding authors upon reasonable request.

\section{References}

17. Xie X. et al. Engineering SARS-CoV-2 using a reverse genetic system. Nat. Protocols https://doi.org/10.1038/s41596-021-00491-8 (2021)

18. Muruato, A. E. et al. A high-throughput neutralizing antibody assay for COVID-19 diagnosis and vaccine evaluation. Nat. Commun. 11, 4059 (2020).

\section{Acknowledgements}

This work was supported by Pfizer and BioNTech. We thank colleagues at Pfizer, BioNTech and the University of Texas Medical Branch for helpful discussions and support during the study. We thank the Pfizer-BioNTech clinical trial C4591001 participants, from whom the post-immunization human sera were obtained. We thank the many colleagues at Pfizer and BioNTech who developed and produced the BNT162b2 vaccine candidate. P.-Y.S. was supported by National Institutes of Health grants AI142759, AI134907, AI145617 and UL1TR001439, and awards from the Sealy \& Smith Foundation, Kleberg Foundation, the John S. Dunn Foundation, the Amon G. Carter Foundation, the Gilson Longenbaugh Foundation and the Summerfield Robert Foundation.

\section{Author contributions}

Conceptualization: X.X., V.D.M., S.C.W. and P.-Y.S.; Methodology: X.X., Y.L., J.L., J.Z., C.R.F.G., H.X. and P.-Y.S; Investigation: X.X., Y.L., J.L., J.Z., C.R.F.G., H.X., K.A.S., D.C., P.R.D. and P.-Y.S; Resources: M.C., D.C., P.R.D. and P.-Y.S; Data curation: X.X., Y.L., J.L., J.Z., C.R.F.G. and P.-Y.S; Writing-original draft: X.X. and P.-Y.S; Writing-review and editing: X.X., P.R.D. and P.-Y.S.; Supervision: X.X., M.C., D.C., P.R.D. and P.-Y.S.; Funding acquisition: P.-Y.S.

\section{Competing interests}

The authors declare competing interests. X.X., V.D.M. and P.-Y.S. have filed a patent on the reverse genetic system. K.A.S., M.C., D.C. and P.R.D. are employees of Pfizer and might hold stock options. X.X., J.Z., C.R.F.G., H.X. and P.-Y.S. received compensation from Pfizer to perform the neutralization assay.

\section{Additional information}

Supplementary information The online version contains supplementary material available at https://doi.org/10.1038/s41591-021-01270-4.

Correspondence and requests for materials should be addressed to P.R.D. or P.-Y.S.

Peer review information Alison Farrell was the primary editor on this article and managed its editorial process and peer review in collaboration with the rest of the editorial team.

Reprints and permissions information is available at www.nature.com/reprints. 


\section{Reporting Summary}

Nature Research wishes to improve the reproducibility of the work that we publish. This form provides structure for consistency and transparency in reporting. For further information on Nature Research policies, see our Editorial Policies and the Editorial Policy Checklist.

\section{Statistics}

For all statistical analyses, confirm that the following items are present in the figure legend, table legend, main text, or Methods section.

n/a Confirmed

\ $\square$ The exact sample size $(n)$ for each experimental group/condition, given as a discrete number and unit of measurement

$\square$ \ A statement on whether measurements were taken from distinct samples or whether the same sample was measured repeatedly

Х The statistical test(s) used AND whether they are one- or two-sided

X Only common tests should be described solely by name; describe more complex techniques in the Methods section.

Х $\square$ A description of all covariates tested

Х $\square$ A description of any assumptions or corrections, such as tests of normality and adjustment for multiple comparisons

A full description of the statistical parameters including central tendency (e.g. means) or other basic estimates (e.g. regression coefficient) AND variation (e.g. standard deviation) or associated estimates of uncertainty (e.g. confidence intervals)

For null hypothesis testing, the test statistic (e.g. $F, t, r$ ) with confidence intervals, effect sizes, degrees of freedom and $P$ value noted

$\bigotimes \square \begin{aligned} & \text { For null hypothesis testing, the test statistic } \\ & \text { Give } P \text { values as exact values whenever suitable. }\end{aligned}$

Х $\square$ For Bayesian analysis, information on the choice of priors and Markov chain Monte Carlo settings

$\bigotimes \square$ For hierarchical and complex designs, identification of the appropriate level for tests and full reporting of outcomes

$\triangle \square$ Estimates of effect sizes (e.g. Cohen's $d$, Pearson's $r$ ), indicating how they were calculated

Our web collection on statistics for biologists contains articles on many of the points above.

\section{Software and code}

Policy information about availability of computer code

Data collection No code and software used for the data collection

Data analysis Graphpad Prism 9

For manuscripts utilizing custom algorithms or software that are central to the research but not yet described in published literature, software must be made available to editors and

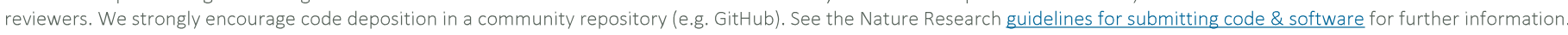

Data

Policy information about availability of data

All manuscripts must include a data availability statement. This statement should provide the following information, where applicable:

- Accession codes, unique identifiers, or web links for publicly available datasets

- A list of figures that have associated raw data

- A description of any restrictions on data availability

The data that support the findings of this study are available from the corresponding authors upon reasonable request. 
Please select the one below that is the best fit for your research. If you are not sure, read the appropriate sections before making your selection.

$\bigotimes$ Life sciences $\quad \square$ Behavioural \& social sciences $\quad \square$ Ecological, evolutionary \& environmental sciences

For a reference copy of the document with all sections, see nature.com/documents/nr-reporting-summary-flat.pdf

\section{Life sciences study design}

All studies must disclose on these points even when the disclosure is negative.

$\begin{array}{ll}\text { Sample size } & \begin{array}{l}\text { No sample size calculation was performed. Based on the availability, } 20 \text { samples were collected from BNT162b2 vaccinees participating in the } \\ \text { phase } 1 \text { portion of the ongoing phase } 1 / 2 / 3 \text { clinical trial (ClinicalTrials.gov identifier: NCT04368728). Those 20 samples had been tested as } \\ \text { neutralizing positive against WT SARS-CoV-2 using the method according to the reference (Walsh EE, Frenck RW, Jr., Falsey AR, et al. Safety } \\ \text { and Immunogenicity of Two RNA-Based Covid-19 Vaccine Candidates. N Engl J Med 2020.). }\end{array} \\ \text { Data exclusions } & \text { No data was excluded in the study. } \\ \text { Replication } & \begin{array}{l}\text { Each human serum sample was analyzed in duplication. The averaged results from the duplication were reported in this study. } \\ \text { Randomization } \\ \text { experimental settings. }\end{array} \\ \text { Blinding } & \begin{array}{l}\text { Patient information was blinded in the study. Those } 20 \text { samples had been tested as neutralizing positive against WT SARS-CoV-2 using the } \\ \text { method according to the reference (Walsh EE, Frenck RW, Jr., Falsey AR, et al. Safety and Immunogenicity of Two RNA-Based Covid-19 Vaccine } \\ \text { Candidates. N Engl J Med 2020.). }\end{array}\end{array}$

\section{Reporting for specific materials, systems and methods}

We require information from authors about some types of materials, experimental systems and methods used in many studies. Here, indicate whether each material, system or method listed is relevant to your study. If you are not sure if a list item applies to your research, read the appropriate section before selecting a response.

\begin{tabular}{|c|c|}
\hline $\mathrm{n} / \mathrm{a}$ & Involved in the study \\
\hline Х & $\square$ Antibodies \\
\hline & $\bigotimes$ Eukaryotic cell lines \\
\hline 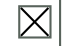 & $\square$ Palaeontology and archaeology \\
\hline Х & $\square$ Animals and other organisms \\
\hline L & $\bigotimes$ Human research participants \\
\hline Х & $\square$ Clinical data \\
\hline Х & $\square$ Dual use research of concern \\
\hline
\end{tabular}

\begin{tabular}{l|l}
\multicolumn{2}{l}{ Methods } \\
\hline n/a & Involved in the study \\
$\searrow$ & $\square$ ChIP-seq \\
$\searrow$ & $\square$ Flow cytometry \\
$\square$ & $\square$ MRI-based neuroimaging
\end{tabular}

Eukaryotic cell lines

Policy information about cell lines

Cell line source(s)

Vero E6 cells (ATCC ${ }^{\circledR}$ CRL-1586) were obtained from ATCC

Authentication

ATCC have comprehensively performed authentication on cell lines.

Mycoplasma contamination

Commonly misidentified lines (See $\underline{\text { ICLAC register) }}$
All cell lines were tested negative for mycoplasma.

not applicable

\section{Human research participants}

\section{Policy information about studies involving human research participants}


Ethics oversight

The protocol and informed consent were approved by institutional review boards for each of the investigational centers participating in the study. The study was conducted in compliance with all International Council for Harmonisation (ICH) Good Clinical Practice (GCP) guidelines and the ethical principles of the Declaration of Helsinki.

Note that full information on the approval of the study protocol must also be provided in the manuscript. 